\title{
Ultrasound-guided transversus abdominis plane blocks for patients undergoing laparoscopic hand-assisted nephrectomy: a randomized, placebo-controlled trial
}

\author{
This article was published in the following Dove Press journal: \\ Local and Regional Anesthesia \\ 25 April 2014 \\ Number of times this article has been viewed
}

\author{
Stephen Aniskevich' \\ C Burcin Taner ${ }^{2}$ \\ Dana K Perry ${ }^{2}$ \\ Christopher B Robards ${ }^{3}$ \\ Steven B Porter ${ }^{3}$ \\ Colleen S Thomas ${ }^{4}$ \\ Ilana I Logvinov ${ }^{5}$ \\ Steven R Clendenen ${ }^{4}$ \\ 'Department of Anesthesia, \\ Division of Transplant Anesthesia, \\ ${ }^{2}$ Department of Transplantation, \\ ${ }^{3}$ Department of Anesthesia, Division \\ of Regional Anesthesia, ${ }^{4}$ Division of \\ Health Sciences Research, Section \\ of Biostatistics, ${ }^{5}$ Department of \\ Anesthesia, Mayo Clinic Florida, \\ Jacksonville, FL, USA
}

\begin{abstract}
Postoperative pain is a common complaint following living kidney donation or tumor resection using the laparoscopic hand-assisted technique. To evaluate the potential analgesic benefit of transversus abdominis plane blocks, we conducted a randomized, double-blind, placebo-controlled study in 21 patients scheduled to undergo elective living-donor nephrectomy or single-sided nephrectomy for tumor. Patients were randomized to receive either $20 \mathrm{~mL}$ of $0.5 \%$ ropivacaine or $20 \mathrm{~mL}$ of $0.9 \%$ saline bilaterally to the transversus abdominis plane under ultrasound guidance. We found that transversus abdominis plane blocks reduced overall pain scores at 24 hours, with a trend toward decreased total morphine consumption. Nausea, vomiting, sedation, and time to discharge were not significantly different between the two study groups. Keywords: transversus abdominis plane block, nephrectomy, kidney donor, ultrasound guidance
\end{abstract}

\section{Introduction}

Patients undergoing nephrectomy have a high incidence of postoperative pain despite the use of modern laparoscopic surgical techniques. In the postoperative period, these patients are often treated with patient-controlled opioids, epidural analgesia, or both. While effective, both of these treatment modalities carry risk, ie, opioids have a side effect profile including pruritus, nausea, and vomiting, and increase the risk of oversedation and apnea in patients at risk (eg, those with sleep apnea). Epidurals have been associated with hypotension, post dural puncture headaches, changes in management of anticoagulation, as well as rare but serious infections, bleeding, and nerve injury. Transversus abdominis plane (TAP) blocks have been described as a way of providing analgesia to the anterior abdominal wall with minimal risk. ${ }^{1}$ These blocks avoid the potential hazards associated with opioids and neuraxial blockade. Use of ultrasound to correctly identify structures during administration of these blocks should theoretically further lessen the risk of complications.

To date, only a handful of prospective randomized studies have been performed examining the clinical utility of TAP blocks related to kidney transplant. The first three studies $^{2-4}$ showed improved pain scores in patients receiving the TAP block, while Frier et $\mathrm{al}^{5}$ showed no benefit. Additionally, Mukhtar and Khattak showed a decrease in nausea in the TAP group. ${ }^{2}$ The aim of this prospective, randomized, double-blind, placebo-controlled study was to evaluate the efficacy of TAP blocks in providing analgesia for patients undergoing laparoscopic hand-assisted nephrectomy for either tumor
Correspondence: Stephen Aniskevich Mayo Clinic Florida, 4500 San Pablo Rd, Jacksonville, FL 32224, USA

Tel + I 9049532000

Fax + I 9049563332

Email aniskevich.stephen2@mayo.edu 
resection or kidney donation. Our hypothesis was that TAP block would result in a significant reduction in both opioid consumption (primary endpoint) and pain scores (secondary endpoint) in the 24-hour period following surgery.

\section{Materials and methods}

The study was approved by the Mayo Clinic institutional review board and registered at ClinicalTrials.gov in January 2010 (ClinicalTrials.gov Identifier NCT01054469). Written, informed consent was obtained from 21 patients aged 23-79 years. Initially, we had planned to enroll 50 patients over 2 years, but recruitment proved slower than anticipated, compounded by a surgeon taking a leave of absence, which prevented that goal from being reached before institutional funding expired.

Patients were enrolled if they were aged 18-80 years and were scheduled to undergo hand-assisted laparoscopic removal of a single kidney for either tumor or living donor nephrectomy. Exclusion criteria included: planned bilateral nephrectomy, pregnancy or lactation, inability or refusal to provide informed consent, inability to comprehend the use of a visual analog scale (VAS), an expressed desire for preemptive antiemetics, a history of opioid tolerance, known prior allergy to amide local anesthetics or any of the study drugs (morphine), and a contraindication to regional nerve block (bleeding disorder, infection at site of block). Patients who were converted to open surgery due to intraoperative complications were considered a screen failure and were excluded from further participation in the study.

Participants were randomized in a double-blind fashion. The randomization chart was prepared by the statistician using the permuted block approach to achieve equal numbers of participants in each group. Participants received either $20 \mathrm{~mL}$ of $0.5 \%$ ropivacaine hydrochloride or $20 \mathrm{~mL}$ of $0.9 \%$ normal saline (placebo) bilaterally. The study medication or placebo was dispensed by the operating room pharmacy and was not disclosed to the anesthesiologist performing the block, administering the anesthesia during the case, or performing the evaluations postoperatively. Patients were given mild sedation consisting of midazolam and fentanyl at the discretion of the investigator prior to administration of the block, as per standard clinical care. They then underwent bilateral TAP block immediately before surgery in the preoperative holding bay. The technique for TAP block is well described and consists of identification of the lumbar "triangle of Petit" and subsequent injection of local anesthetic into the fascial plane between the internal oblique and transversus muscles using ultrasound guidance to ensure proper placement. ${ }^{6,7}$
Participants received standard general anesthesia induction doses of propofol (2-3 mg/kg), fentanyl (up to $250 \mu \mathrm{g}$ ), and vecuronium or cisatracurium (titrated to maintain train-offour at one twitch using a nerve stimulator). Anesthesia was maintained with isoflurane at 1 minimum alveolar concentration (MAC) with intermittent fentanyl boluses to a maximum of $250 \mu \mathrm{g}$. Fentanyl was not administered after initiation of skin closure. No pre-emptive antiemetics were administered. Postoperatively, participants were given intravenous patient-controlled morphine analgesia dosed at $1 \mathrm{mg}$ with an 8-minute lockout. For inadequate pain control, defined as a pain score $>4$, the dose was increased to $1.5 \mathrm{mg}$ every 8 minutes. Rescue doses were administered at the discretion of the attending physician. Ideally, only morphine sulfate was to be used for breakthrough pain. If another opioid was administered, we converted the dose, using standard tables, to morphine equivalents. We assessed pain score (at rest and with movement) using a VAS at 0, 2, 6, 12, and 24 hours postoperatively. Pain scores were recorded as 0 (no pain) to 10 (worst pain ever). Additionally, we assessed the time to first request for analgesia and the total amount of morphine at each time interval. We also assessed the presence of postoperative nausea and vomiting, the need for rescue antiemetics, and the level of sedation recorded as 0 (awake and alert), 1 (appears asleep but awakes easily), 2 (asleep, difficult to arouse), or 3 (deep sleep). All patients complaining of nausea and requesting an antiemetic were treated with ondansetron $4 \mathrm{mg}$. This dose could be repeated if needed.

Surgical exposure was obtained using either a $7 \mathrm{~cm}$ supraumbilical or infraumbilical midline incision and 2-3 laparoscopic port entry sites as determined by the surgeon. Incisions for the port sites ranged from $5 \mathrm{~mm}$ to $12 \mathrm{~mm}$ and were on the ipsilateral side. Intra-abdominal insufflation with carbon dioxide was limited to $15 \mathrm{mmHg}$.

\section{Statistical analysis}

Study data were collected and managed using REDCap (Research Electronic Data Capture) tools hosted at Mayo Clinic. REDCap is a secure, web-based application designed to support data capture for research studies. It provides an interface for data entry, audit trails, automated export to statistical programs, and procedures for importing data from an external source. ${ }^{8}$

Numerical variables were primarily summarized with the sample median (minimum, 25th percentile, 75th percentile, maximum) while categorical variables were summarized with number and percentage. In the evaluation of all primary and secondary aims, comparison of treatment groups 
(placebo versus active) was performed using Fisher's exact test for categorical variables and the Wilcoxon rank-sum test for continuous variables, while time to first request of opiates was evaluated using the log-rank test. The data were analyzed using SAS version 9.2 (SAS Institute Inc., Cary, NC, USA). $P$-values $\leq 0.05$ were considered to be statistically significant.

The study was designed to enroll 50 patients (25 per group), and was estimated to have $80 \%$ power to detect a $14 \mathrm{mg}$ difference in opiate consumption. With the smaller than planned sample size, the possibility of a type II error should be considered when interpreting the results.

\section{Results}

The characteristics for all 21 participants and for those in the placebo versus active treatment groups are summarized in Table 1. Participants ranged in age from 23 to 79 (median 53) years of age and $12(57 \%)$ were male. The median operative time was 217 minutes in the active treatment group and 168 minutes in the group that received placebo, while median length of stay was 2 days in both groups. There were no complications related to TAP block placement.

Comparison of postoperative opiate consumption between the two groups is summarized in Table 2. Median 24-hour total opiate consumption was lower in the active treatment group than in the placebo group (26.6 $\mathrm{mg}$ versus $48.7 \mathrm{mg}, P=0.13$, respectively). The median amount of time after surgery until the first request for morphine by the participant was 59 minutes in the active treatment group and 50 minutes in the placebo group $(P=0.37)$.

Post-surgical abdominal pain, as measured by the VAS, was compared between the two groups (Table 3). There was no evidence of a difference in VAS pain scores between the two groups during the first 12 hours after surgery, either at rest (all $P \geq 0.47$ ) or with bending of the knee (all $P \geq 0.62$ ).
However, at 24 hours after surgery, median VAS pain scores were significantly lower for the active treatment group compared with the placebo group, both at rest (1 versus 4 , $P=0.017$ ) and with bending of the knee ( 1 versus 5, $P=0.002$ ). Although we did not formally evaluate the trend in pain scores over time, there is some evidence of a trend toward increased pain scores over the 24-hour post-surgery time period in the placebo group (Table 3 ).

The incidence of nausea and vomiting after surgery is compared between the two groups in Table 4. There was a trend toward a lower incidence of nausea in the 24 hours after surgery in the active treatment group compared with the placebo group ( $50 \%$ versus $91 \%, P=0.064)$. However, there was no evidence of a difference in incidence of vomiting during the 24 hours after surgery between the two groups ( $20 \%$ versus $20 \%, P=1.00)$. There were significantly fewer requests for an antiemetic after surgery in the active treatment group than in the placebo group ( $50 \%$ versus $100 \%, P=0.012$ ).

The post-surgery sedation scores are compared for the two patient groups in Table 5. The placebo group was more sedated than the active treatment group immediately after surgery, with eight $(73 \%)$ patients in the placebo group versus only two patients $(20 \%)$ in the active treatment group ( $P=0.009$ ) being either asleep or in a deep sleep. There was no evidence of a difference in sedation level between the two groups at 2 and 24 hours after surgery (all $P \geq 0.58$ ).

\section{Discussion}

As ultrasound-guided techniques have improved the efficacy and safety of TAP blocks, there has been a renewed interest in their use to provide analgesia to the anterior abdominal wall. Multiple studies support the theory that TAP blocks are effective in controlling pain for a variety of upper and lower abdominal surgeries. ${ }^{6,7,9,10}$ However, recent evidence suggests that these blocks may not be equally effective for all types

Table I Patient characteristics

\begin{tabular}{|c|c|c|c|}
\hline Variable $^{a}$ & Overall $(n=21)$ & Placebo $(n=I I)$ & Active $(n=10)$ \\
\hline Age at surgery, years & $53(23-79)$ & $53(40-79)$ & $53(23-74)$ \\
\hline Male & $12(57 \%)$ & $6(60 \%)$ & $6(55 \%)$ \\
\hline Body mass index, $\mathrm{kg} / \mathrm{m}^{2}$ & $24.3(20.0-31.9)$ & $25.0(20.0-31.9)$ & $23.9(22.0-30.2)$ \\
\hline Side of surgery, left & $16(76 \%)$ & $7(70 \%)$ & $9(82 \%)$ \\
\hline Operative time (minutes) & $181(102-269)$ & $168(102-224)$ & $217(109-269)$ \\
\hline Minutes from needle insertion to block completion ${ }^{\mathrm{b}}$ & $15(4-33)$ & $13(4-33)$ & $15(10-20)$ \\
\hline Blood reflux from needle ${ }^{c}$ & $0(0 \%)$ & $0(0 \%)$ & $0(0 \%)$ \\
\hline $\begin{array}{l}\text { Time from end of surgery to Foley catheter } \\
\text { removal (hours) }\end{array}$ & $19.9(17.6-382.9)$ & $20.0(17.6-330.9)$ & $19.9(18.8-382.9)$ \\
\hline Days from surgery to discharge & $2(2-6)$ & $2(2-4)$ & $2(2-6)$ \\
\hline
\end{tabular}

Notes: ${ }^{a}$ Categorical variables are reported as $n(\%)$, continuous variables are reported with median (minimum, maximum); bfour patients in the placebo group and two in the active group did not have needle insertion time collected; 'two placebo patients did not have blood reflux from needle data collected. 
Table 2 Postoperative morphine consumption

\begin{tabular}{|c|c|c|c|}
\hline Variable $^{a}$ & Placebo $(n=I I)$ & Active $(n=10)$ & $P$-value ${ }^{b}$ \\
\hline Total pain medication at hour 0 (mg) & $0.0(0.0,0.0,1.7,6.7)$ & $0.0(0.0,0.0,0.0,0.0)$ & 0.094 \\
\hline Total pain medication at hour $2(\mathrm{mg})$ & $6.7(0.0,2.6,10.0,12.0)$ & $2.0(0.0,0.0,7.2,20.0)$ & 0.38 \\
\hline Total pain medication at hour 6 (mg) & $10.7(0.0,3.3,14.6,28.6)$ & $6.6(0,2.2,9.9,34.8)$ & 0.50 \\
\hline Total pain medication at hour $12(\mathrm{mg})$ & $8.0(0.0,5.3,14.7,28.0)$ & $8.8(0.0,4.1,10.0,20.0)$ & 0.83 \\
\hline Total pain medication at hour 24 (mg) & $12.7(0.0,6.6,37.0,55.5)$ & $9.0(0.0,3.3,10.0,97.3)$ & 0.20 \\
\hline Total 24-hour opiate consumption (mg) & $48.7(14.0,24.4,73.3,84.6)$ & $26.6(11.7,16.5,36.3,151.3)$ & 0.13 \\
\hline Minutes from end of surgery to first PCA & $50(16,36,90,166)$ & $59(30,48,115,455)$ & $0.37^{c}$ \\
\hline
\end{tabular}

morphine request

Notes: ${ }^{a}$ Continuous variables are reported with median (minimum, 25 th percentile, 75 th percentile, maximum); ${ }^{b} P$-value given based on $W$ ilcoxon rank sum test; ${ }^{c} P$-value given based on log rank test.

Abbreviation: PCA, patient-controlled morphine analgesia.

of surgery. ${ }^{5,11-13}$ This variation may be due to differences in the technique, timing, or amount of local anesthetic used. ${ }^{10}$ In this study, we investigated whether TAP blocks would be effective in providing analgesia to patients undergoing hand-assisted laparoscopic nephrectomy in the hope that we could improve patient satisfaction with regard to pain, nausea, and somnolence.

In our small randomized study, there was a trend, albeit not statistically significant, towards a decrease in total opiate consumption in the 24 hours after nephrectomy among patients who received the TAP block compared with those who received a sham TAP block with saline (placebo).

Table 3 Abdominal pain score post surgery at rest and with bending knee

\begin{tabular}{|c|c|c|c|}
\hline Variable $^{a}$ & $\begin{array}{l}\text { Placebo } \\
(n=I I)\end{array}$ & $\begin{array}{l}\text { Active } \\
(\mathrm{n}=10)\end{array}$ & $P$-value \\
\hline $\begin{array}{l}\text { VAS pain score } \\
\text { at rest hour } 0\end{array}$ & $\mathrm{I}(0,0,6,10)^{\mathrm{b}}$ & $0(0,0,6,10)$ & 0.85 \\
\hline $\begin{array}{l}\text { VAS pain score } \\
\text { at rest hour } 2\end{array}$ & $2(0,0,5,10)$ & I $(0,0,3,6)$ & 0.61 \\
\hline $\begin{array}{l}\text { VAS pain score } \\
\text { at rest hour } 6\end{array}$ & $2(0,1,5,10)$ & $3(0,2,4,6)$ & 0.89 \\
\hline $\begin{array}{l}\text { VAS pain score } \\
\text { at rest hour } 12\end{array}$ & $3(1,1,4,10)$ & $2(0,1,5,5)$ & 0.47 \\
\hline $\begin{array}{l}\text { VAS pain score } \\
\text { at rest hour } 24\end{array}$ & $4(0,2,6,8)$ & $\mathrm{I}(0,0,2,4)$ & 0.017 \\
\hline $\begin{array}{l}\text { VAS pain score with } \\
\text { bending knee hour } 0\end{array}$ & $\mathrm{I}(0,0,6,10)^{\mathrm{b}}$ & $0(0,0,6,10)$ & 0.85 \\
\hline $\begin{array}{l}\text { VAS pain score with } \\
\text { bending knee hour } 2\end{array}$ & $2(0,0,6,10)^{b}$ & I $(0,0,4,6)$ & 0.68 \\
\hline $\begin{array}{l}\text { VAS pain score with } \\
\text { bending knee hour } 6\end{array}$ & $2(0,0,5,10)$ & $3(0,0,4,7)$ & 0.97 \\
\hline $\begin{array}{l}\text { VAS pain score with } \\
\text { bending knee hour } 12\end{array}$ & $4(0,1,6,10)$ & $3(0,0,5,7)$ & 0.62 \\
\hline $\begin{array}{l}\text { VAS pain score with } \\
\text { bending knee hour } 24\end{array}$ & $5(2,3,7,10)$ & $\mathrm{I}(0,0,2,6)$ & 0.002 \\
\hline
\end{tabular}

Notes: ${ }^{a}$ Continuous variables are reported with median (minimum, 25 th percentile, 75 th percentile, maximum); ${ }^{b}$ information was not collected for one patient; ${ }^{c} P$-value given based on Wilcoxon rank sum test.

Abbreviation: VAS, visual analog scale.
This observation is consistent with prior published studies, which have shown improved pain control in the first 24 hours postoperatively. ${ }^{14-16}$ This improvement in overall pain is also reflected by the decrease in pain scores at 24 hours, at both rest and with movement. The resulting decrease in opioid consumption may also be the reason for the parallel decrease in incidence of nausea in the active group when compared with the placebo group. The benefit gained in pain relief at 24 hours did not translate to improved time to discharge or overall sedation scores.

The use of TAP blocks in transplant anesthesia is growing. They have been described for kidney transplant recipients, ${ }^{2,3,5}$ liver transplant, ${ }^{17}$ and in control of immediate postoperative pain following pancreas transplant. ${ }^{18}$ To date, only one prospective study has described the use of TAP blocks in kidney donors. ${ }^{4}$ Hosgood et al administered $0.375 \%$ bupivacaine using a similar technique to that used in this study. ${ }^{4}$ We chose

Table 4 Nausea and vomiting post surgery

\begin{tabular}{|c|c|c|c|}
\hline Variable $^{a}$ & $\begin{array}{l}\text { Placebo } \\
(n=11)\end{array}$ & $\begin{array}{l}\text { Active } \\
(n=10)\end{array}$ & $P$-value ${ }^{c}$ \\
\hline Nausea hour 0 & $2(20 \%)^{b}$ & $2(20 \%)$ & 1.00 \\
\hline Nausea hour 2 & $3(27 \%)$ & $2(20 \%)$ & 1.00 \\
\hline Nausea hour 6 & $5(45 \%)$ & $4(40 \%)$ & 1.00 \\
\hline Nausea hour 12 & $3(27 \%)$ & $2(20 \%)$ & 1.00 \\
\hline Nausea hour 24 & $3(30 \%)^{b}$ & I (I0\%) & 0.58 \\
\hline $\begin{array}{l}\text { Any nausea within } 24 \text { hours } \\
\text { after surgery }\end{array}$ & 10 (91\%) & $5(50 \%)$ & 0.064 \\
\hline Vomiting hour 0 & $0(0 \%)^{b}$ & $0(0 \%)$ & NA \\
\hline Vomiting hour 2 & $0(0 \%)^{b}$ & $0(0 \%)$ & NA \\
\hline Vomiting hour 6 & I $(10 \%)^{b}$ & I (I0\%) & 1.00 \\
\hline Vomiting hour 12 & I $(10 \%)^{b}$ & I (I0\%) & 1.00 \\
\hline Vomiting hour 24 & $0(0 \%)^{b}$ & $0(0 \%)$ & NA \\
\hline $\begin{array}{l}\text { Any vomiting within } 24 \text { hours } \\
\text { after surgery }\end{array}$ & $2(20 \%)^{b}$ & $2(20 \%)$ & 1.00 \\
\hline Requested antiemetic after surgery & II (I00\%) & $5(50 \%)$ & 0.012 \\
\hline
\end{tabular}

Notes: ${ }^{2}$ Categorical variables are reported as $\mathrm{n}(\%)$, continuous variables are reported with median (minimum, 25th percentile, 75th percentile, maximum); binformation was not collected for one patient; ${ }^{C} P$-value given based on Fisher's exact test unless otherwise specified. 
Table 5 Sedation post surgery

\begin{tabular}{|c|c|c|c|}
\hline Variable $^{a}$ & $\begin{array}{l}\text { Placebo } \\
(n=I I)\end{array}$ & $\begin{array}{l}\text { Active } \\
(n=10)\end{array}$ & $P$-value ${ }^{b}$ \\
\hline Sedation hour 0 & & & 0.009 \\
\hline Awake and alert & $0(0 \%)$ & I (I0\%) & \\
\hline Awakens easily & $3(27 \%)$ & 7 (70\%) & \\
\hline Asleep & $8(73 \%)$ & $\mathrm{I}(10 \%)$ & \\
\hline Deep sleep & $0(0 \%)$ & I (I0\%) & \\
\hline Sedation hour 2 & & & 0.67 \\
\hline Awake and alert & $0(0 \%)$ & I (I0\%) & \\
\hline Awakens easily & $9(82 \%)$ & 7 (70\%) & \\
\hline Asleep & $2(18 \%)$ & I (I0\%) & \\
\hline Deep sleep & $0(0 \%)$ & I (I0\%) & \\
\hline Sedation hour 6 & & & 1.00 \\
\hline Awake and alert & $4(36 \%)$ & $4(40 \%)$ & \\
\hline Awakens easily & 7 (64\%) & $6(60 \%)$ & \\
\hline Asleep & $0(0 \%)$ & $0(0 \%)$ & \\
\hline Deep sleep & $0(0 \%)$ & $0(0 \%)$ & \\
\hline Sedation hour 12 & & & 0.67 \\
\hline Awake and alert & 5 (45\%) & $6(60 \%)$ & \\
\hline Awakens easily & $6(55 \%)$ & $4(40 \%)$ & \\
\hline Asleep & $0(0 \%)$ & $0(0 \%)$ & \\
\hline Deep sleep & $0(0 \%)$ & $0(0 \%)$ & \\
\hline Sedation hour 24 & & & 0.58 \\
\hline Awake and alert & 10 (91\%) & $8(80 \%)$ & \\
\hline Awakens easily & I (9\%) & $2(20 \%)$ & \\
\hline Asleep & $0(0 \%)$ & $0(0 \%)$ & \\
\hline Deep sleep & $0(0 \%)$ & $0(0 \%)$ & \\
\hline
\end{tabular}

Notes: a Categorical variables are reported as $\mathrm{n}(\%)$; ${ }^{\mathrm{b}} \mathrm{P}$-value given based on Fisher's exact test.

ropivacaine due to its safer cardiovascular risk profile in the event of accidental intravascular injection. ${ }^{19}$ As in our study, Hosgood et al found that pain scores were reduced at 24 and 48 hours. Additionally, total morphine consumption was significantly less in the first 6 hours (active, $12.4 \mathrm{mg}$; control, $21.2 \mathrm{mg} ; P=0.015)$ but the difference lost its statistical significance over 48 hours. Hosgood et al also showed no benefit with regard to time to discharge or rates of nausea/ vomiting, but did show improved sedation scores in the control group.

Due to the finite duration of action associated with a single injection of local anesthetic, addition of a catheter for continuous infusion may improve pain control in these patients. Jankovic et $\mathrm{al}^{3}$ described intraoperative placement of a catheter by the surgeon into the space between the transversus muscle and the internal oblique. This resulted in improved pain control in seven patients when compared with a historical group. They found that prior attempts to place the catheter transcutaneously resulted in a high failure rate. Subcostal approaches to catheter placement have been described. ${ }^{20,21}$ More studies looking at this modality in relation to living kidney donors are needed to fully assess its viability.
This study is not without limitations. Its small sample size prevented formal analysis of trends in opiate consumption, abdominal pain, nausea, vomiting, and sedation over time. Although we did find some significant differences between the two groups, our study still lacked power, and therefore the possibility of a type II error (ie, a false negative association) should be considered. Additionally, in order to maintain a blinded study, skin sensation was not assessed prior to surgery. In clinical practice, adequacy of the block would have been assessed prior to skin incision. In an attempt to minimize this variance, ultrasound was used and a regional anesthesiologist with experience in TAP blocks performed the procedures.

In summary, we found that TAP blocks reduced overall pain scores at 24 hours, with a trend toward decreased total morphine consumption. Nausea, vomiting, sedation, and time to discharge were not significantly different between the two study groups. Further large-scale studies should be undertaken to fully evaluate the clinical utility of this technique in renal transplant patients as well as in patients undergoing resection for tumor.

\section{Acknowledgment}

This research was supported by the Scholarly Opportunity Award and the Center for Translational Science Activities grant (UL1 TR000135).

\section{Author contributions}

SA: study design, block placement, analysis of data, and drafting the manuscript. CBR: study design and, performance of blocks and review of the final manuscript. DKP: study design and manuscript review. CBT: study design, analysis of data, and manuscript review. SBP: analysis of data, performance of blocks and manuscript review. CST: manuscript review and statistical analysis. IL: study design, data collection, and manuscript review. SRC: study concept design, performance of blocks and review of the final manuscript.

\section{Disclosure}

The authors report no conflicts of interest in this work.

\section{References}

1. Yarwood J, Berrill A. Nerve blocks of the anterior abdominal wall Continuing Education in Anaesthesia, Critical Care and Pain. 2010;10: $182-186$.

2. Mukhtar K, Khattak I. Transversus abdominis plane block for renal transplant recipients. Br J Anaesth. 2010;104:663-664.

3. Jankovic ZB, Pollard SG, Nachiappan MM. Continuous transversus abdominis plane block for renal transplant recipients. Anesth Analg 2009;109:1710-1711

4. Hosgood SA, Thiyagarajan UM, Nicholson HF, et al. Randomized clinical trial of transversus abdominis plane block versus placebo in live donor nephrectomy. Transplantation. 2012;94:520-525. 
5. Frier NM, Murphy C, Mugawar M, et al. Transversus abdominis plane block for analgesia in renal transplantation: a randomized controlled trial. Anesth Analg. 2012;115:953-957.

6. McDonnell JG, ODonnell B, Curley G, et al. The analgesic efficacy of transversus abdominis plane block after abdominal surgery. A prospective randomized controlled study. Anesth Analg. 2007;104:193-197.

7. El-Dawlatly AA, Turkistani A, Kettner SC, et al. Ultrasound guided transversus abdominis plane block: description of a new technique and comparison with conventional systemic analgesia during laparoscopic cholecystectomy. Br J Anaesth. 2009;102:763-767.

8. Harris PA, Taylor R, Thielke R, et al. Research electronic data capture (REDCap) - a metadata-driven methodology and workflow process for providing translational research informatics support. J Biomed Inform. 2009; 42:377-381.

9. Johns N, O’Neill S, Ventham N, Barron F, Brady R, Daniel T. Clinical effectiveness of transversus abdominis plane (TAP) block in abdominal surgery: a systematic review and meta-analysis. Colorectal Dis. 2012;14:e635-e642.

10. Abdallah FW, Chan VW, Brull R. Transversus abdominis plane block. A systematic review. Reg Anesth Pain Med. 2012;37:193-209.

11. Costello JF, Moore AR, Wieczorek PM, et al. The transversus abdominis plane block, when used as part of a multimodal regimen inclusive of intrathecal morphine, does not improve analgesia after cesarean delivery. Reg Anesth Pain Med. 2009;34:586-589.

12. Griffiths JD, Middle JV, Barron FA, et al. Transversus abdominis plane block does not provide additional benefit to multimodal analgesia in gynecological cancer surgery. Anesth Analg. 2010;111:797-801.

13. McMorrow RC, Ni Mhuircheartaigh RJ, Ahmed KA, et al. Comparison of transversus abdominis plane block vs spinal morphine for pain relief after caesarean section. Br J Anaesth. 2011;106:706-712.
14. Sforza M, Andejelkov K, Zaccheddu R, Nagi H, Colic M. Transversus abdominis plane block anesthesia in abdominoplasties. Plast Reconstr Surg. 2011;128:529-535.

15. Ra YS, Kim CH, Lee GY, Han JI. The analgesic effect of the ultrasound guided transverse abdominis plane block after laparoscopic cholecystectomy. Korean J Anesthesiol. 2010;58:362-368.

16. De Oliveira GS, Fitzgerald PC, Marcus RJ, et al. A dose ranging study of the effect of transversus abdominis block on postoperative quality of recovery and analgesia after outpatient laparoscopy. Anesth Analg. 2011;113:1218-1225.

17. Milan ZB, Duncan B, Rewari V, et al. Subcostal transversus abdominis plane block for postoperative analgesia in liver transplant recipients. Transplant Proc. 2011;43:2687-2690.

18. Aniskevich S, Clendenen SR, Torp KD. Bilateral transversus abdominis plane block for managing pain after pancreas transplant. Exp Clin Transplant. 2011;9:277-278.

19. Lefrant JY, de La Coussaye JE, Ripart J, et al. The comparative electrophysiologic and hemodynamic effects of a large dose of ropivicaine and bupivacaine in anesthetized and ventilated piglets. Anesth Analg. 2001;93:1598-1605.

20. Niraj G, Kelkar A, Jeyapalan I, et al. Comparison of analgesic efficacy of subcostal transversus plane blocks with epidural analgesia following upper abdominal surgery. Anaesthesia. 2011;66:465-471.

21. Hebbard PD, Barrington MJ, Vasey C. Ultrasound guided continuous oblique subcostal transversus abdominus plane blockade: description of anatomy and clinical technique. Reg Anesth Pain Med. 2010;35: 436-441.
Local and Regional Anesthesia

\section{Publish your work in this journal}

Local and Regional Anesthesia is an international, peer-reviewed, open access journal publishing on the development, pharmacology, delivery and targeting and clinical use of local and regional anesthetics and analgesics. The journal welcomes submitted papers covering original research, basic science, clinical studies, reviews \& evaluations,

\section{Dovepress}

guidelines, expert opinion and commentary, case reports and extended reports. The manuscript management system is completely online and includes a very quick and fair peer-review system, which is all easy to use. Visit http://www.dovepress.com/testimonials.php to read real quotes from published authors. 